\title{
Spontaneous Renal Artery Dissection Resulting in Renal Infarction: A Case Report and Review of the Literature
}

\author{
Yoorim Seo, Ji Won Min, Yong Kyun Kim, Ho Cheol Song and Myung Ah Ha
}

\begin{abstract}
:
Spontaneous renal artery dissection is a rare disease and an uncommon cause of renal infarction. The patient was a man who presented to the emergency room with sudden-onset right flank pain. Computed tomography revealed right renal infarction; thus, anticoagulation was initiated. Renal angiography revealed luminal narrowing of the segmental artery to the superior pole of right kidney without a dissection flap or false lumen. We stopped anticoagulation due to a lack of evidence of thrombi or luminal narrowing of the dissected vessels. When patients present with acute flank pain, it is important to suspect renal infarction and to perform a correct diagnostic workup, even when the patient shows normal urinalysis results and a normal LDH value.
\end{abstract}

Key words: spontaneous renal artery dissection, renal infarction, acute flank pain

(Intern Med Advance Publication)

(DOI: 10.2169/internalmedicine.2530-18)

\section{Introduction}

Renal infarction (RI) is a rare disease that is most commonly caused by cardiogenic thromboembolism associated with underlying diseases such as atrial fibrillation, intracardiac thrombus, infective endocarditis, and valvular heart disease (1). Less common causes of RI include hypercoagulation disorders, hematologic disease, and spontaneous renal artery dissection (SRAD) (2). Renal artery dissection is most commonly caused by the progression of a dissecting aneurysm of the aorta (3). Most cases are accompanied by an underlying disease such as malignant hypertension, Marfan syndrome, Ehlers-Danlos syndrome, neurofibromatosis, syphilitic arteritis, tuberculosis, and polyarteritis nodosa (4). Spontaneous dissection occurring in the renal arteries without any known trauma or underlying disease is termed SRAD (5). This case report describes the diagnostic workup and treatment of an otherwise healthy man with RI due to SRAD.

\section{Case Report}

A 37-year-old man presented to our emergency room with sudden-onset right flank pain. The pain persisted for a few hours without radiation or worsening on movement. He had no complaints of symptoms such as dysuria, gross hematuria or systemic symptoms such as fever, fatigue or joint ache. A physical examination at the time of presentation revealed the following findings: blood pressure (BP), 130/90 $\mathrm{mmHg}$; heart rate (HR), 78 beats per minute (bpm); and body temperature, $36.8^{\circ} \mathrm{C}$. He had no history of relevant medical conditions including hypertension or recent physical trauma. On physical examination, his abdomen was soft and flat with normal bowel sounds; however, right costovertebral angle tenderness was observed. He had no features related to Marfan syndrome, Ehlers-Danlos syndrome, neurofibromatosis or Takayasu arteritis. A blood analysis revealed the following findings: white blood cell count, $12,450 / \mathrm{mm}^{3}$ (neutrophils $71.5 \%$, lymphocytes $23.3 \%$ ); hemoglobin level, $17.9 \mathrm{~g} /$ dL; lactate dehydrogenase (LDH), 185 IU/L; creatine phosphokinase, $124 \mathrm{U} / \mathrm{L}$; blood urea nitrogen (BUN), $12.8 \mathrm{mg} /$ $\mathrm{dL}$; creatinine $(\mathrm{Cr}), 0.85 \mathrm{mg} / \mathrm{dL}$ : and C-reactive protein

Division of Nephrology, Department of Internal Medicine, Bucheon St. Mary's Hospital, College of Medicine, The Catholic University of Korea, Korea

Received: December 14, 2018; Accepted: February 24, 2019; Advance Publication by J-STAGE: June 27, 2019

Correspondence to Dr. Myung Ha, hamyunga@naver.com 


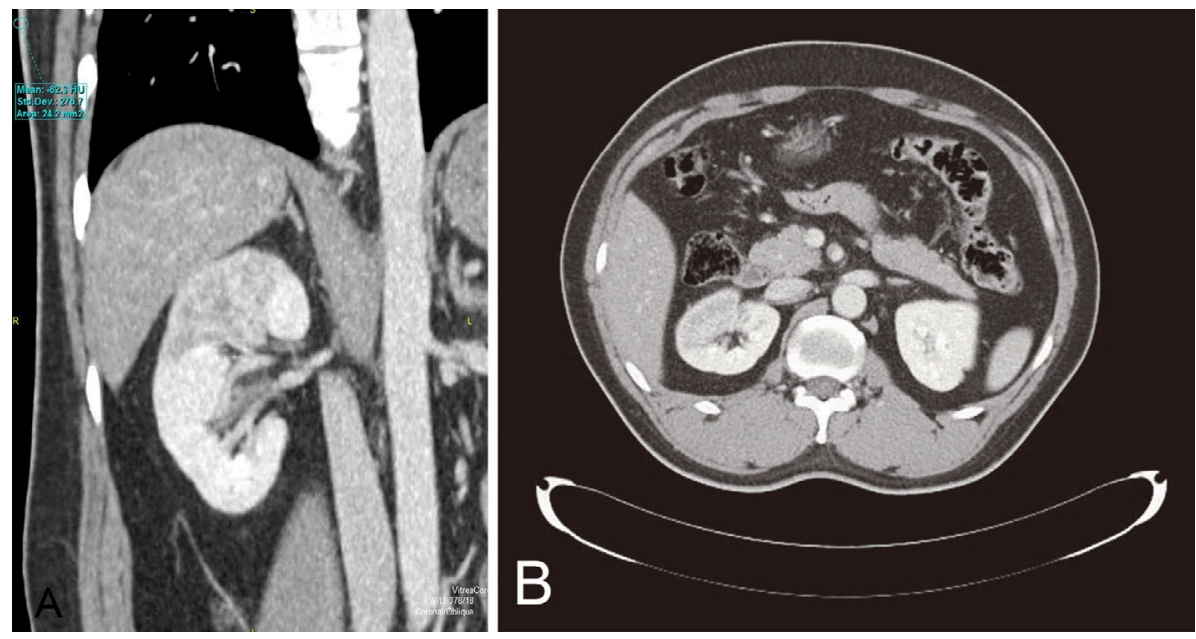

Figure 1. Abdominopelvic computed tomography images of right renal infarction. (A) Coronal view. (B) Horizontal view.
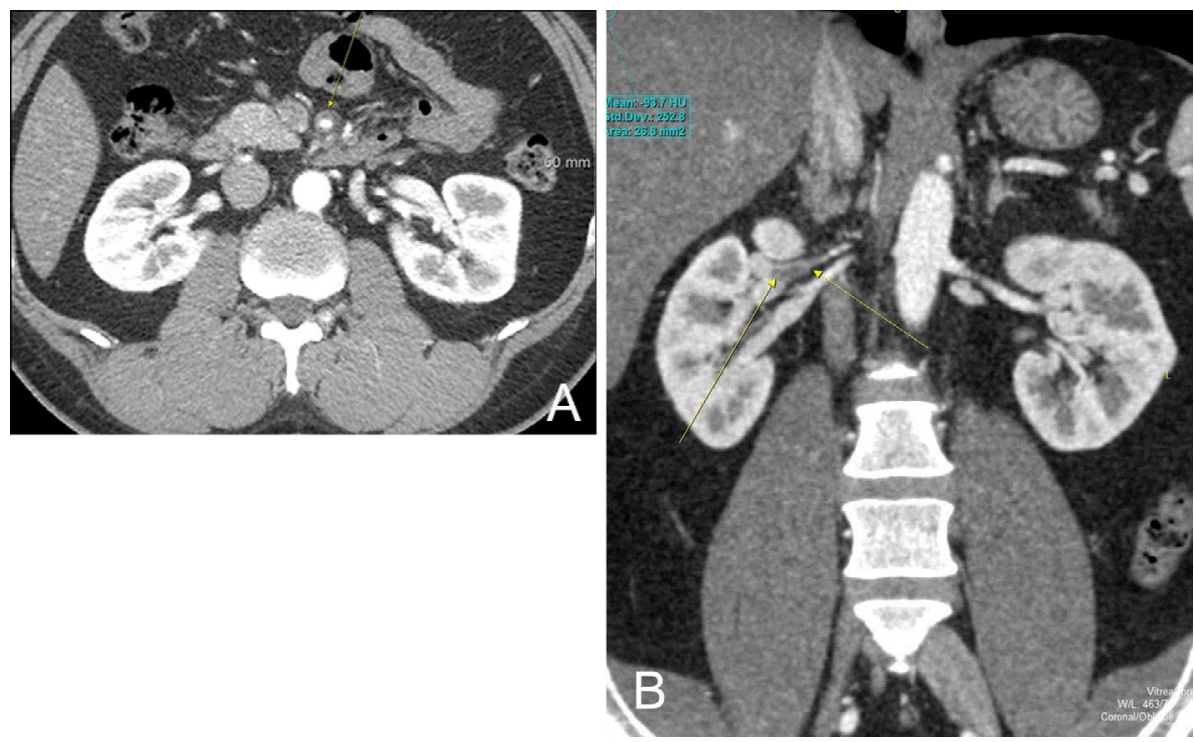

Figure 2. APCT. (A) Horizontal view of SMA dissection. (B) Coronal view of right renal artery dissection.

(CRP), $2.65 \mathrm{mg} / \mathrm{L}$. The other results of blood and urine analyses were within the normal ranges. The patient's urine sediment showed no evidence of proteinuria or hematuria. Electrocardiography showed rare atrial premature complexes (APCs), with an HR of $71 \mathrm{bpm}$. A plain X-ray of the abdomen showed normal findings. Abdominopelvic computed tomography (APCT) showed a wedge-shaped perfusion defect in the superior portion of the right kidney with cortical rim enhancement, which suggested acute infarction (Fig. 1). The intimal flap, a characteristic finding of vessel dissection on CT scans, was observed in an area of low mural attenuation along the superior mesenteric artery (SMA) and the superior segmental branch of the right renal artery (Fig. 2). The jejunum seemed intact without ischemic changes. Anticoagulation therapy was started with low molecular weight heparin (LMWH; $1 \mathrm{mg} / \mathrm{kg}$ per 12 hours) for 3 days together with warfarin. We performed coagulation tests to exclude coagu- lopathy and the results were within the normal ranges (Table). On 24-hour Holter monitoring, rare APCs were observed but no arrhythmia (e.g., atrial fibrillation or atrial flutter) were seen. Echocardiography showed no evidence of thrombi or vegetation. The patient's vital signs were stable without fever and his flank pain subsided during hospital admission. Laboratory tests showed no deterioration of the renal function and no hematuria or pyuria; however, his CRP level was elevated from $2.65 \mathrm{mg} / \mathrm{L}$ to $9.81 \mathrm{mg} / \mathrm{L}$. Renal artery angiography was performed on the fifth hospital day. The exam revealed luminal narrowing of the segmental artery leading to the superior pole of the right kidney without a dissection flap or false lumen. Flow limitation was not seen on angiography at this time (Fig. 3A). SMA angiography showed luminal narrowing of the proximal SMA without flow limitation and the intimal flap seen in the initial APCT was not observed on angiography at this time 
Table. Coagulation Test Results.

\begin{tabular}{lcc}
\hline \multicolumn{1}{c}{ Blood test } & Test value & Reference range \\
\hline Prothrombine time(s) / INR & $10.8 / 0.92$ & $10.1-14.0 / 0.85-1.13$ \\
Activated partial thromboplastin time(s) & 28.1 & $21.0-38.0$ \\
D-dimer (mg/L) & 0.19 & $0-0.55$ \\
C protein activity (\%) & 116 & $70-130$ \\
S protein activity (\%) & 85 & $77-143$ \\
Lupus anticoagulant Ab & Negative & Negative \\
Anti cardiolipin Ab IgM/IgG & 1.4 & Negative/Negative \\
Anti phospholipid IgG(GPL/mL) & Negative & Negative \\
Factor V Leiden mutation & 69 & $60-120$ \\
Anti-thrombin III $(\%)$ & 283 & $180-415$ \\
Fibrinogen (mg/dL) & 85 & $60-150$ \\
Factor VIII $(\%)$ & 102 & $66-126$ \\
Factor V $(\%)$ & & \\
\hline
\end{tabular}
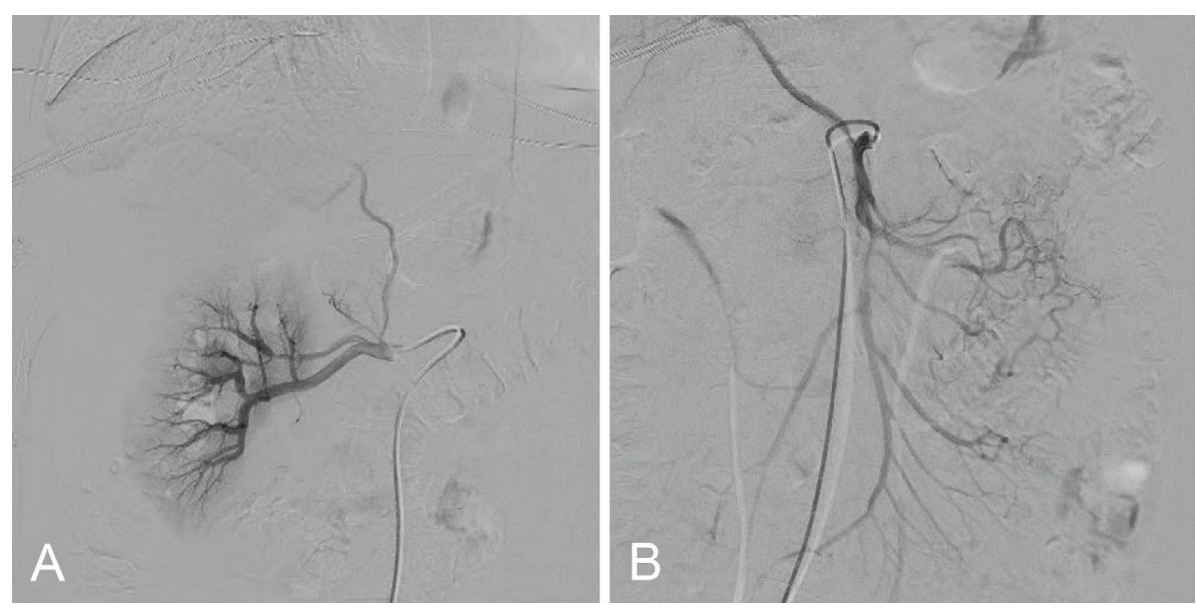

Figure 3. Angiography. (A) Right renal angiography. (B) SMA angiography.

(Fig. 3B). After angiography, we stopped anticoagulation therapy because there was no evidence of thrombi or flow limitation in the dissected vessels. He was hospitalized for 8 days and his BP was checked three times (5:00 a.m., 12:00 p.m., and 6:00 p.m.) a day during his hospital stay. During hospitalization, his systolic BP ranged from 110 to 140 and his diastolic BP ranged from 70 to 90 without any hypertensive medications.

At one week after discharge, the patient visited the outpatient clinic. He was generally in a good condition and had a normal renal function. His BP was $150 / 80 \mathrm{mmHg}$. Twentyfour-hour ambulatory blood pressure monitoring (ABPM) was performed to diagnose hypertension. His 24-hour average BP was 144.9/91.4 $\mathrm{mmHg}$, his day-time average BP was 148.4/94.5 and his night-time average BP was 134.8/ $82.5 \mathrm{mmHg}$. According to the 24-hour ABPM, he was diagnosed with hypertension and antihypertensive medication was initiated (carvedilol [25 mg, once daily]). On a followup visit, his BP was 130/80 $\mathrm{mmHg}$; thus, the antihypertensive medication was continued at the same dose.

\section{Discussion}

Spontaneous renal artery dissection is a rare disease and only 200 reports have been made since the first report in 1944 (6). A quarter of these cases were discovered on autopsy (2). The condition predominantly occurs in males (4:1 ratio) in their fourth to sixth decade of life (1). The incidence of SRAD in each kidney has been considered to be similar; however, a recent case series reported that the left side is more frequently involved (2). One hypothesis suggests that physical exercise can cause renal artery dissection by stretching the arterial wall $(7,8)$. The right kidney artery is perhaps affected less frequently than the left side, due to its longer length, which may cause shear stress to be more evenly distributed. Bilateral involvement was reported in 10$15 \%$ of the cases and was more frequently associated with underlying arterial disease (9-11).

The clinical presentation of SRAD ranges from lifethreatening hypertension to renal failure. Hypertension may in turn also act as an aggravating factor for arterial dissection by potentiating arteriosclerosis and medial degenera- 
tion (4). There are three different clinical manifestations of SRAD: an indolent state with no apparent progression; a renal infarction state due to an acute occlusion; and a chronic state with renovascular hypertension (1). The formation of a true and false lumen in the renal artery due to the rupture of the intimal layer in SRAD, may result in the obstruction of all or a part of the renal artery, thereby resulting in RI. In cases of RI, such as the case of our patient, the diagnosis should be made as quickly as possible to increase the possibility of renal revascularization and spare the renal parenchyma from further ischemic damage. In previous cases of RI, the AST, ALP and LDH levels were found to be increased, with accompanying proteinuria and/or hematuria (12). However, as was observed in the present case, some patients may show normal urinalysis results and LDH levels that are within the normal range on their initial presentation to the hospital (13).

Although there have been reports of cases in which SRAD was diagnosed by intravascular ultrasound (14), ultrasound and Doppler ultrasound show poor sensitivity (4). SRAD is most commonly diagnosed by CT angiography or MRA. Invasive exploration with angiography is recommended at an early stage to demonstrate the extent and nature of the vascular lesion, and to determine whether endovascular treatment is feasible. The results may also serve as a baseline vascular state to be used for comparison in follow-up studies (9). On angiography, thromboemboli and dissection appear differently; emboli appear as a meniscus crossing the width of the artery, whereas dissection is visualized as a linear filling defect in the arterial lumen or as uniform narrowing due to non-filling of the false lumen (7).

The optimal treatment of SRAD has not been established, and treatment should be selected based on the anatomical features of the dissection, the patient's hemodynamic status and the renal function. The importance of BP control is uncontroversial, as previous reports have shown that BP control is the only treatment to have a significant effect on patient outcomes $(1,5)$. Although previous studies on the treatment of RI due to SRAD with oral anticoagulation and anti-hypertensive medication showed that the renal function remained stable with no significant complications $(15,16)$, its usefulness remains controversial. In the case of our patient, anticoagulation was stopped after renal artery angiography because no flow limitation or thrombi were observed. A Normal renal function was maintained without subsequent recurrence. Further studies are needed to establish guidelines for the use of anticoagulants in SRAD. The failure of medical treatment for BP control may require surgical treatments or other interventions (10). Percutaneous endovascular treatment with long-term follow-up has proven to be associated with less use of antihypertensive medications, less target organ damage and lower complication rates in comparison to surgical or medical treatment alone (17). If serial angiography shows a stable lesion without aggravation of the renal function, careful follow up is reasonable. However, if repeat angiography reveals an unstable lesion or if refractory hy- pertension is present, some form of intervention may be required (9). Surgical management, such as aorto-renal bypass, has also been recommended for the treatment of renovascular hypertension and acute occlusion (18). Primary nephrectomy may also be considered if the kidney is already severely damaged by infarction with a poor function on isotope renography and if revascularization is considered difficult to achieve $(18,19)$.

In patients presenting with acute flank or abdominal pain but with normal urinalysis results and normal LDH, BUN and $\mathrm{Cr}$ values, it is important to still consider RI and to perform an optimal diagnostic workup. In this patient, RI occurred due to SRAD, but angiography showed resolution without further intervention such as ballooning or stenting. As in previous reports, a favorable prognosis may be expected in young patients with RI due to SRAD without any underlying disease.

The authors state that they have no Conflict of Interest (COI).

Funding Sources: There is no Funding Source.

\section{Author Contributions}

Conceptualization: Song HC

Investigation: Seo YR, Ha MA

Writing - original draft preparation: Seo YR

Writing - review and editing: Ha MA

Approval of the final manuscript: Min JW, Song HC

\section{ORCID}

The names of authors should be same as those in the title page.

Yoorim Seo https://orcid.org/0000-0002-3691-5814

Ji Won Min https://orcid.org/0000-0001-6295-8095

Yong Kyun Kim https://orcid.org/0000-0002-1871-3549

Ho Cheol Song https://orcid.org/0000-0002-9849-8091

Myung Ah Ha https://orcid.org/0000-0003-3056-1709

\section{References}

1. Yoon K, Song SY, Lee CH, et al. Spontaneous Renal Artery Dissection as a Cause of Acute Renal Infarction: Clinical and MDCT Findings. J Korean Med Sci 32: 605-612, 2017.

2. Bourgault M, Grimbert $P$, Verret $C$, et al. Acute renal infarction: a case series. Clin J Am Soc Nephrol 8: 392-398, 2013.

3. Mathieu D, Abbou C, Meunier S, Larde D, Vasile N. Primary Dissecting Aneurysm of the Renal Artery. Urol Radiol 5: 17-21, 1983.

4. Gandhi SP, Patel K, Pal BC. Isolated Spontaneous Renal Artery Dissection Presented with Flank Pain. Case Rep Radiol 2015: 896706, 2015.

5. Beroniade V, Roy P, Froment D, Pison C. Primary renal artery dissection. Presentation of two cases and brief review of the literature. Am J Nephrol 7: 382-389, 1987.

6. Bumpus HC Jr. A case of renal hypertension. Trans Am Assoc Genitourin Surg 37: 135-140, 1945.

7. Alamir A, Middendorf DF, Baker P, Nahman NS Jr, Fontaine AB, Hebert LA. Renal artery dissection causing renal infarction in otherwise healthy men. Am J Kidney Dis 30: 851-855, 1997.

8. Thomas MC, Walker RJ, Packer S. Running repairs: renal artery 
dissection following extreme exertion. Nephrol Dial Transplant 14: 1258-1259, 1999.

9. Mudrick D, Arepally A, Geschwind J-F, Ronsivalle JA, Lund GB, Scheel P. Spontaneous Renal Artery Dissection: Treatment with Coil Embolization. J Vasc Interv Radiol 14: 497-500, 2003.

10. Lacombe M. Isolated spontaneous dissection of the renal artery. J Vasc Surg 33: 385-391, 2001.

11. Mori H, Hayashi K, Tasaki T, Hori T, Yamasaki T, Amamoto Y Spontaneous resolution of bilateral renal artery dissection: a case report. J Urol 135: 114-116, 1986.

12. Lee JG, Joo KW, Na KY, et al. Renal Infarction: Retrospective Analysis of Clinical Features in 27 Cases. Korean J Nephrol 12: 598-608, 1993.

13. Oh SJ, Kim H-Y, Kwon SG, et al. A Case of Spontaneous Renal Artery Dissection Causing Renal Infarction in a Previously Healthy Man. Korean J Nephrol 5: 831-836, 2002.

14. Watanabe $Y$, Aramoto $H$, Asano R, Furuichi S, Sumiyoshi $T$, Takanashi S. Iatrogenic renal artery dissection uncommon complication during aortic endovascular repair. JACC Cardiovasc Interv 3: $986-987,2010$
15. Ramamoorthy SL, Vasquez JC, Taft PM, McGinn RF, Hye RJ. Nonoperative management of acute spontaneous renal artery dissection. Ann Vasc Surg 16: 157-162, 2002.

16. Renaud S, Leray-Moragues H, Chenine L, Canaud L, Vernhet-Kovacsik H, Canaud B. Spontaneous renal artery dissection with renal infarction. Clin Kidney J 5: 261-264, 2012.

17. Pellerin $\mathrm{O}$, Garcon $\mathrm{P}$, Beyssen B, et al. Spontaneous renal artery dissection: long-term outcomes after endovascular stent placement. J Vasc Interv Radiol 20: 1024-1030, 2009.

18. Misrai V, Peyromaure M, Poiree S, Marteau V, Laurian C. Spontaneous dissection of branch renal artery- is conservative management safe and effective? J Urol 176: 2125-2129, 2006.

19. Muller BT, Reiher L, Pfeiffer T, et al. Surgical treatment of renal artery dissection in 25 patients: indications and results. J Vasc Surg 37: 761-768, 2003.

The Internal Medicine is an Open Access journal distributed under the Creative Commons Attribution-NonCommercial-NoDerivatives 4.0 International License. To view the details of this license, please visit (https://creativecommons.org/licenses/ by-nc-nd/4.0/).

\section{(C) The Japanese Society of Internal Medicine} Intern Med Advance Publication 